\title{
THE EXISTENCE OF THE DAY-OF-THE-WEEK EFFECT
}

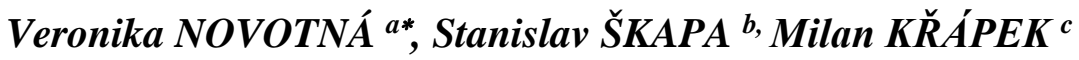 \\ ${ }^{a, b, c}$ Brno University of Technology, Czech Republic
}

DOI: $10.24818 / \mathrm{IMC} / 2020 / 05.01$

\begin{abstract}
Both market participants and numerous academics and experts strive to understand the behaviour of financial markets, more specifically the movements investment instruments' prices and generation of profits. As early as in the 1980s, expert studies began to emerge, which, thanks to empirical testing, discovered certain phenomena in the markets that were in conflict with the theory of efficient markets due to the below-average or above-average return potential of investment instruments. These phenomena are referred to as anomalies disrupting the theory of efficient markets.

In this paper, the authors aim to verify the existence of the so-called "day of the week effect" in selected capital markets. The following methods will be used to achieve the goal: analysis, comparison and deduction. Specifically, analysis will be used, for example, to analyse the properties describing individual types of anomalies. Comparison will focus, for example, on comparing the results of empirical testing between selected periods and then it shall evaluate the conclusions following from these results for selected markets. Deduction will help examine whether the stated hypothesis is able to fully explain the presence of anomalies in the financial market.
\end{abstract}

KEYWORDS: finantial markets, efficient markets, day of the week effect

\section{INTRODUCTION}

The efficient market hypothesis was created based on the results of empiric studies, and nowadays constitutes an important part of the modern financial theory. The efficient market hypothesis concept concerns the behaviour of prices of securities or stock exchange indices, while its fundamental idea was formulated in the form of the efficient market hypothesis, for its validity has not been clearly proved or refuted yet. Therefore, the matter of market efficiency is still up-to-date, primarily for investors who have been trying to discover an investment strategy through which it would be possible to get above-average returns, and also for economists who have been trying to understand and explain the behaviour of prices of financial instruments on capital markets based on a generally valid model. The question whether the stock market is efficient and what form of efficiency it shows, has not been resolved to date. There are studies confirming a weak form of efficiency in some stock markets in highly developed countries, such as the United Kingdom and the USA. But likewise, there are studies and surveys that disconfirm any semi-strong or even weak form of stock market efficiency. These studies have brought evidence that there are certain anomalies, situations or effects in the markets that persist or recur regularly, the existence of which makes it possible for investors to achieve above-average returns on a long-term and recurring basis, which is contrary to the characteristics of an efficient market.

In this article, the authors aim to verify the existence of the "day-of-the week effect" in certain capital markets. The primary data used were obtained at www.bloomberg.com.

\footnotetext{
* Corresponding author. E-mail address: novotna@fbm.vutbr.cz
} 


\section{THE EFFICIENT MARKET HYPOTHESIS}

The first references about the efficient market hypothesis can be found in articles by Bachlier from 1900. His work also explained the theory of stochastic processes in commodity prices, being completely original, but without receiving much attention at the time. Furthermore, it appeared in an empiric research conducted by Cowles in 1937. But it was Samuelson who outlined the concept of the modern efficient market hypothesis for the first time (Samuelson, 1973).

A comprehensive efficient market hypothesis was first formulated by Eugene Fama in the 60s and 70s of the previous centuries. In his work (Fama, 1970), he summarised the theory known to date, and above all the empiric results available. He implanted the definition of efficient capital markets in its simplest form into the general framework of the efficient market in economic terms, i.e. a market where the prices "fully" incorporate all available information. His work was followed by many renowned financial economists, such as R. A. Brealey, S. C. Myers, J. C. Francis or R. A. Haugen, who defines the efficient market as a place where the stock prices reflect all the information that is possible to know and that is significant (Haugen, 2000). Fama himself (Fama, 1991) later used a more general definition set deeper into economic terms, where prices reflect the information available to the extent that the marginal benefit of using the information is equal to the marginal cost of acquisition thereof. Malkiel (2003) defines capital markets as efficient if buyers are not able to achieve excessive returns without accepting excessive risk.

\section{BASIC ASSUMPTIONS}

The efficient market hypothesis is currently the most significant stream in economics. The theory says that the stock market is efficient and contains price-creating information nearly immediately (relevant information spreads in 30 seconds as maximum). This is the reason why business strategies fail because the price is always objective and adjusts to its internal value, and price movements are affected only by unexpected information, hence the prices change unexpectedly, too.

By the efficiency power we distinguish three basic forms:

Weak efficiency form - the stock price contains all historical information, and therefore it is not possible to predict the stock price based on the previous price curve, which casts doubts on the technical analysis.

Semi-strong efficiency form - the stock price contains all historical and current public information, which casts doubts on the fundamental analysis, too.

Strong efficiency form - the stock price contains all information, including the non-publicly available.

Many researches concerning the efficient market hypothesis have been carried out, but only the weak and semi-strong efficiency forms were confirmed. It is confirmed that there is non-public information accessible only to elect professionals who thus achieve above-average returns. This fact is also supported by Liu Yongxin in his study (2009).

Efficiency tests are divided into the same groups as the forms thereof. Therefore, Fama in his later work again introduces three groups, but with modified names, giving a better description of the testing procedures (Fama, 1991). The new test groups are returns prediction tests (for the weak form), case studies (for the semi-strong form) and private information tests (for the strong form). If we want to examine the semi-strong form of efficient capital markets, we first have to check the basic assumption whether the markets are at least weakly efficient.

\subsection{Market Anomalies}

In the foregoing paragraphs, we studied the efficient market hypothesis based on assumptions, rules, and regularities. Over the time, market movements and variations started to appear, which were contrary to the efficient market notion. The movements showing some time relation or a relation with a certain recurring event, started to be referred to as anomalies. 
In general, an anomaly refers to a concept where a variation from the normal status occurs and the phenomenon is hard to understand or to explain with the existing available computer equipment. Many economists claim that after an anomaly is explained and documented, this anomaly often disappears, reverses, or attenuates (Khuntia and Pattanyak, 2018).

Market anomalies are particularities in the behaviour of securities that cannot simply be explained on the statistical basis, and sometimes are hard to explain on the economic basis. Frequently, the solution to such issues is the approach explaining anomalies based on the particularities of behaviour of economic players. It is hard to explain in economic terms why securities should be traded on Wednesdays more than any other day, for example.

Anomalies found in financial markets can be divided into two groups:

- Effects confirming market efficiency

- Effects disconfirming market efficiency.

Effects confirming market efficiency are not conventional representatives of anomalies. The notion of anomaly should be a situation where the market efficiency is put to doubt or the event fails to follow the market prerequisites for efficiency. For our interest and purposes, we will thus study only anomalies that are contrary to the market efficiency hypothesis (Al-Khazali and Mirzaei,2017) We can further divide anomalies to seasonal and other, i.e. whether their occurrence depends on a time period of the year or not. Seasonal anomalies can refer to a certain month of the year, such as the January effect and September effect, or a certain day of the month, such as the Monday effect and Weekend effect. Other anomalies are fundamental and technical anomalies, of which fundamental anomalies are more obvious, easier to understand and more comprehensible.

\subsection{The Day-of-the-Week Effect}

The day-of-the-week effect describes the behaviour of stock prices according to a certain pattern during the business week. It means a certain seasonal character of the stock price behaviour in the week, which is contrary to the random walk as assumed by the efficient market. According to this effect, any seasonality or regularity in stock markets could be used for the construction of successful trading strategies generating above-average returns, which, however, is again contrary to the efficient market. The day-of-the-week effect, or else the Monday effect, has been studied by economists for a long time, and its existence is therefore a topic for discussion in literature, too.

Cross (2018) was among the first ones to confirm the relation between average stock returns and the day of the week using data from the USA. These results were confirmed by (Fama and French, 1993), who says that the Monday returns are lower in general compared to other business days.

In 1981, economists Gibbons and Hess (1981) attempted to prove the Monday effect in their study examining the stock price fluctuation using the Standard and Poor's 500 stock index over the period of 6 years, namely between 1962-1968. The S\&P 500 stock index measures the stock performance of 500 American companies taking into account many factors, such as the industry branch of the company, the size of the market capitalisation and the level of liquidity. On the other hand, Lakonishok and Smidt (1988) did not find any proof of the day-of-the-week existence on a global level.

Connolly (1989) found out that the existence of the day-of-the-week effect is related to the time period and the technique of statistical calculations used in the USA, and (Chang et al., 1993) found clear evidence of the day-of-the-week effect in European markets. In their publication, Sias and Starks (1995) explain why anomalies of the day-of-the-week effect occur. Using the S\&P 500 index, Fortune (1998) ascertains statistically relevant negative returns on weekends before and after 1987.

Most of the studies that have been made to date document the situation, especially in the American market. Works studying the level of efficiency in other countries appear only sporadically, and if they do, they concern highly developed countries, such as the UK, Germany, or Japan. Nonetheless, in respect of the Czech capital market, there is a study testing its efficiency - the publication (Filáček, 
Kapička and Vošvrda, 1998). The authors came to the conclusion that the Czech capital market does not reach even the weak form of efficiency, having tested the period from 1995 to 1997.

In Brasil, (Madureira and Leal, 2001) found that the day-of-the-week effect depends on time and that it disappears in certain periods.

(Bildik, 2004), studied the Istanbul stock market from the point of view of the day-of-the-week anomaly existence finding out that the stock return was considerably higher on Friday than on Monday. His explanation is that investors usually trade less on Mondays, and hence the returns are lower on Mondays than on the other business days. (Golder and Macy, 2011) further found out that there is evidence supporting the fact that the Monday effect may be explained by the investors' reactions to negative news and notices published on Friday. Over the week, the mood usually gets better compared to Monday, which could be the reason why Monday returns are lower.

According to (Zhang et al., 2017), the day-of-the-week effect may influence investors when deciding about the selection of their portfolios for their global investment strategies. Zhang et al. (2017) claim that this kind of phenomena cannot be explained adequately based on the financial theory.

\section{METHODOLOGY AND DATA}

In this work, we have selected as observed indices the price weighted Dow Jones Industrial Average Index and the value weighted S\&P 500 and NASDAQ Composite. We have also analysed the PX Index representing the Prague Stock Exchange, which was chosen on the grounds of its short history.

We have studied the day-of-the-week effect in the years 1995-2018 using data available at www.bloomberg.com.

For all the indices obtained, we use the following variables

$I_{t}^{o}$ - Open index value in time $\mathrm{t}$

$I_{t}^{c}$ - Close index value in time $\mathrm{t}$

$I_{r t^{-}}^{o}$ Open index value on the first day of the year corresponding to time t.

To get a higher informative value, the effects were determined using three variables.

The daily growth percentage variable (PD) is defined as the ratio of the closing day price and opening day price. Then we subtract 1 from the result for the resulting variable to indicate the percentage by which the index has grown in a day.

$$
P D=\frac{I_{t}^{o}}{I_{t}^{c}}-1
$$

The second variable gives the daily growth percentage related to the beginning of the year (PDR) and is defined as the ratio of the index daily difference to the opening value at the beginning of the year.

$$
P D R=\frac{I_{t}^{c}-I_{t}^{o}}{I_{r t}^{o}}
$$

The last variable used is the difference of the daily percentage growth (DDP), calculated as the difference in the ratios of the close index values and values at the beginning of the year. These ratios indicate the percentage of change compared to the beginning of the year. The difference then means the change that occurred in the observed day. In this variable, we always lose the first day of 
each year because its value would not be comparable to the previous day, for they each relate to a different reference value (the beginning of another year).

$$
D D P=\frac{I_{t}^{c}}{I_{r t}^{c}}-\frac{I_{t+1}^{c}}{I_{r t}^{c}}
$$

To be able to analyse the effect of the days in the week, we determined averages and standard deviations of the variables for each day of the week, and likewise the averages and standard deviations of the other days, for each index and each year.

Further, we determined using the F-test and T-test whether the average value for the examined day is statistically significantly different from the average of the other days. Thus, for each index and each examined variable, we obtained a matrix of p-values for each year and day.

To get a result that will not be affected by only one manner of calculation of the examined variable, we determined a geometrical average of the p-values, giving each variable the same weight. The result is an average probability that the difference of the average value of the examined variable in the examined day and the average of the other days is statistically insignificant.

\section{ANALYSIS OF RESULTS}

We can see in the tables below the geometrical averages of p-values in the t-tests, where we compare average values of the examined days of the week and average values of the other days.

Table 1. The geometrical averages of p-values 1995-2000

\begin{tabular}{|c|c|c|c|c|c|c|c|}
\hline & Index/Year & $\mathbf{1 9 9 5}$ & $\mathbf{1 9 9 6}$ & $\mathbf{1 9 9 7}$ & $\mathbf{1 9 9 8}$ & $\mathbf{1 9 9 9}$ & $\mathbf{2 0 0 0}$ \\
\hline \multirow{4}{*}{ Monday } & IXIC & 0.316 & 0.118 & 0.253 & 0.479 & 0.193 & 0.004 \\
\cline { 2 - 8 } & GSPC & 0.265 & 0.283 & 0.340 & 0.285 & 0.395 & 0.120 \\
\cline { 2 - 8 } & DX & 0.043 & 0.138 & 0.333 & 0.222 & 0.250 & 0.175 \\
\cline { 2 - 8 } Tuesday & PX & 0.898 & 0.635 & 0.149 & 0.659 & 0.893 & 0.252 \\
\cline { 2 - 8 } & IXIC & 0.265 & 0.283 & 0.340 & 0.285 & 0.395 & 0.120 \\
\cline { 2 - 8 } & GSPC & 0.099 & 0.176 & 0.000 & 0.108 & 0.001 & 0.278 \\
\cline { 2 - 8 } & DX & 0.265 & 0.029 & 0.026 & 0.266 & 0.002 & 0.343 \\
\hline \multirow{5}{*}{ Thursday } & PX & 0.851 & 0.963 & 0.118 & 0.847 & 0.735 & 0.867 \\
\cline { 2 - 8 } & IXIC & 0.148 & 0.154 & 0.028 & 0.283 & 0.304 & 0.013 \\
\cline { 2 - 8 } & GSPC & 0.406 & 0.409 & 0.044 & 0.236 & 0.079 & 0.004 \\
\cline { 2 - 8 } & DX & 0.391 & 0.032 & 0.225 & 0.098 & 0.051 & 0.102 \\
\cline { 2 - 8 } & PX & 0.776 & 0.198 & 0.194 & 0.348 & 0.628 & 0.014 \\
\cline { 2 - 8 } & IXIC & 0.142 & 0.474 & 0.007 & 0.006 & 0.210 & 0.287 \\
\hline & DX & 0.190 & 0.487 & 0.009 & 0.011 & 0.441 & 0.075 \\
\hline \multirow{5}{*}{ Friday } & PX & 0.637 & 0.474 & 0.352 & 0.108 & 0.778 & 0.177 \\
\cline { 2 - 8 } & GSIC & 0.379 & 0.439 & 0.256 & 0.129 & 0.187 & 0.057 \\
\cline { 2 - 8 } & DSC & 0.281 & 0.284 & 0.363 & 0.161 & 0.092 & 0.284 \\
\cline { 2 - 8 } & PX & 0.202 & 0.160 & 0.291 & 0.380 & 0.130 & 0.177 \\
\hline
\end{tabular}

Source:Own calculation 
Table 2. The geometrical averages of p-values 2001-2006

\begin{tabular}{|c|c|c|c|c|c|c|c|}
\hline & Index/Year & 2001 & 2002 & 2003 & 2004 & 2005 & 2006 \\
\hline \multirow{4}{*}{ Monday } & IXIC & 0.408 & 0.323 & 0.345 & 0.442 & 0.124 & 0.317 \\
\hline & GSPC & 0.452 & 0.324 & 0.427 & 0.398 & 0.097 & 0.288 \\
\hline & $\mathrm{DX}$ & 0.361 & 0.396 & 0.385 & 0.374 & 0.152 & 0.270 \\
\hline & $\mathrm{PX}$ & 0.922 & 0.725 & 0.489 & 0.318 & 0.495 & 0.722 \\
\hline \multirow{4}{*}{ Tuesday } & IXIC & 0.452 & 0.324 & 0.427 & 0.398 & 0.097 & 0.288 \\
\hline & GSPC & 0.409 & 0.066 & 0.188 & 0.210 & 0.093 & 0.447 \\
\hline & DX & 0.204 & 0.036 & 0.038 & 0.257 & 0.253 & 0.402 \\
\hline & $\mathrm{PX}$ & 0.969 & 0.153 & 0.222 & 0.212 & 0.398 & 0.213 \\
\hline \multirow{4}{*}{ Wednesday } & IXIC & 0.392 & 0.020 & 0.081 & 0.214 & 0.425 & 0.013 \\
\hline & GSPC & 0.489 & 0.021 & 0.078 & 0.343 & 0.457 & 0.036 \\
\hline & $\mathrm{DX}$ & 0.218 & 0.010 & 0.070 & 0.302 & 0.427 & 0.014 \\
\hline & $\mathrm{PX}$ & 0.626 & 0.523 & 0.457 & 0.245 & 0.297 & 0.485 \\
\hline \multirow{4}{*}{ Thursday } & IXIC & 0.084 & 0.451 & 0.408 & 0.147 & 0.371 & 0.387 \\
\hline & GSPC & 0.060 & 0.421 & 0.250 & 0.241 & 0.481 & 0.440 \\
\hline & $\mathrm{DX}$ & 0.103 & 0.348 & 0.109 & 0.298 & 0.440 & 0.336 \\
\hline & $\mathrm{PX}$ & 0.627 & 0.374 & 0.736 & 0.685 & 0.701 & 0.292 \\
\hline \multirow{4}{*}{ Friday } & IXIC & 0.050 & 0.430 & 0.427 & 0.160 & 0.473 & 0.045 \\
\hline & GSPC & 0.049 & 0.447 & 0.359 & 0.218 & 0.335 & 0.075 \\
\hline & DX & 0.167 & 0.449 & 0.030 & 0.171 & 0.338 & 0.018 \\
\hline & $\mathrm{PX}$ & 0.616 & 0.621 & 0.137 & 0.326 & 0.731 & 0.389 \\
\hline
\end{tabular}

Source:Own calculation

Table 3. The geometrical averages of p-values 2007-2012

\begin{tabular}{|c|c|c|c|c|c|c|c|}
\hline & Index/Year & $\mathbf{2 0 0 7}$ & $\mathbf{2 0 0 8}$ & $\mathbf{2 0 0 9}$ & $\mathbf{2 0 1 0}$ & $\mathbf{2 0 1 1}$ & $\mathbf{2 0 1 2}$ \\
\hline \multirow{4}{*}{ Monday } & IXIC & 0.462 & 0.390 & 0.463 & 0.095 & 0.264 & 0.308 \\
\cline { 2 - 8 } & GSPC & 0.273 & 0.249 & 0.459 & 0.097 & 0.227 & 0.427 \\
\cline { 2 - 8 } & DX & 0.087 & 0.061 & 0.409 & 0.294 & 0.226 & 0.235 \\
\cline { 2 - 8 } Tuesday & PX & 0.812 & 0.867 & 0.769 & 0.002 & 0.159 & 0.210 \\
\cline { 2 - 8 } & IXIC & 0.273 & 0.249 & 0.459 & 0.097 & 0.227 & 0.427 \\
\cline { 2 - 8 } & GSPC & 0.384 & 0.035 & 0.193 & 0.200 & 0.063 & 0.371 \\
\cline { 2 - 8 } & DX & 0.397 & 0.108 & 0.340 & 0.255 & 0.006 & 0.407 \\
\hline \multirow{5}{*}{ Wednesday } & PX & 0.676 & 0.552 & 0.713 & 0.223 & 0.465 & 0.806 \\
\cline { 2 - 8 } & IXIC & 0.064 & 0.084 & 0.314 & 0.112 & 0.194 & 0.181 \\
\cline { 2 - 8 } & GSPC & 0.034 & 0.087 & 0.241 & 0.101 & 0.143 & 0.205 \\
\hline \multirow{5}{*}{ Thursday } & DX & 0.010 & 0.207 & 0.241 & 0.077 & 0.043 & 0.272 \\
\cline { 2 - 8 } & IXIC & 0.741 & 0.785 & 0.898 & 0.392 & 0.048 & 0.869 \\
\cline { 2 - 8 } & GSPC & 0.132 & 0.451 & 0.247 & 0.394 & 0.447 & 0.142 \\
\cline { 2 - 8 } & DX & 0.212 & 0.250 & 0.411 & 0.309 & 0.422 & 0.381 \\
\cline { 2 - 8 } & PX & 0.822 & 0.859 & 0.381 & 0.563 & 0.585 & 0.698 \\
\hline
\end{tabular}




\begin{tabular}{|c|c|c|c|c|c|c|c|}
\hline & Index/Year & $\mathbf{2 0 0 7}$ & $\mathbf{2 0 0 8}$ & $\mathbf{2 0 0 9}$ & $\mathbf{2 0 1 0}$ & $\mathbf{2 0 1 1}$ & $\mathbf{2 0 1 2}$ \\
\hline \multirow{4}{*}{ Friday } & IXIC & 0.461 & 0.438 & 0.284 & 0.077 & 0.452 & 0.431 \\
\cline { 2 - 8 } & GSPC & 0.441 & 0.350 & 0.259 & 0.102 & 0.434 & 0.461 \\
\cline { 2 - 8 } & DX & 0.270 & 0.299 & 0.373 & 0.283 & 0.385 & 0.318 \\
\cline { 2 - 8 } & PX & 0.455 & 0.638 & 0.417 & 0.054 & 0.815 & 0.491 \\
\hline
\end{tabular}

Source:Own calculation

Table 4. The geometrical averages of p-values 2013-2014

\begin{tabular}{|c|c|c|c|c|c|c|c|}
\hline & Index/Year & 2013 & 2014 & 2015 & 2016 & 2017 & 2018 \\
\hline \multirow{4}{*}{ Monday } & IXIC & 0.047 & 0.304 & 0.474 & 0.442 & 0.170 & 0.349 \\
\hline & GSPC & 0.026 & 0.175 & 0.385 & 0.420 & 0.262 & 0.249 \\
\hline & $\mathrm{DX}$ & 0.096 & 0.139 & 0.219 & 0.331 & 0.379 & 0.178 \\
\hline & $\mathrm{PX}$ & 0.596 & 0.655 & 0.724 & 0.671 & 0.383 & 0.205 \\
\hline \multirow{4}{*}{ Tuesday } & IXIC & 0.026 & 0.175 & 0.385 & 0.420 & 0.262 & 0.249 \\
\hline & GSPC & 0.181 & 0.139 & 0.281 & 0.350 & 0.356 & 0.174 \\
\hline & DX & 0.382 & 0.048 & 0.135 & 0.376 & 0.284 & 0.087 \\
\hline & $\mathrm{PX}$ & 0.553 & 0.361 & 0.693 & 0.799 & 0.442 & 0.662 \\
\hline \multirow{4}{*}{ Wednesday } & IXIC & 0.190 & 0.493 & 0.176 & 0.418 & 0.324 & 0.328 \\
\hline & GSPC & 0.163 & 0.335 & 0.124 & 0.367 & 0.385 & 0.428 \\
\hline & $\mathrm{DX}$ & 0.135 & 0.242 & 0.290 & 0.392 & 0.270 & 0.449 \\
\hline & $\mathrm{PX}$ & 0.399 & 0.924 & 0.501 & 0.261 & 0.732 & 0.530 \\
\hline \multirow{4}{*}{ Thursday } & IXIC & 0.474 & 0.285 & 0.208 & 0.369 & 0.209 & 0.419 \\
\hline & GSPC & 0.399 & 0.271 & 0.172 & 0.446 & 0.075 & 0.325 \\
\hline & $\mathrm{DX}$ & 0.295 & 0.323 & 0.301 & 0.230 & 0.075 & 0.395 \\
\hline & $\mathrm{PX}$ & 0.664 & 0.550 & 0.374 & 0.224 & 0.915 & 0.447 \\
\hline \multirow{4}{*}{ Friday } & IXIC & 0.072 & 0.345 & 0.078 & 0.235 & 0.270 & 0.349 \\
\hline & GSPC & 0.017 & 0.463 & 0.103 & 0.280 & 0.070 & 0.363 \\
\hline & DX & 0.015 & 0.190 & 0.300 & 0.392 & 0.104 & 0.439 \\
\hline & PX & 0.635 & 0.438 & 0.555 & 0.767 & 0.655 & 0.059 \\
\hline
\end{tabular}

Source:Own calculation

If the day-of-the-week effect occurs, we can expect that the average returns will be different each day of the week. As we can see in the tables above, the day-of-the-week effect occurs very sporadically. If we analyse all the indices at a time, we have to say that the occurrence of the dayof-the-week effect in all four indices and in the same year was not observed. However, if we analyse the results after removing the PX Index, which can behave differently as a less developed market, we come to the following conclusions:

Monday effect can only be observed in $2013(\mathrm{p}=0.1)$.

Tuesday shows statistically significant anomalies in 1997 (growth, $\mathrm{p}=0.01$ ), 1999 (decrease, $\mathrm{p}=0.01$ ) and 2002 (decrease, $\mathrm{p}=0.05$ ).

Wednesday in the years 2002, 2006 and 2007 shows a growth $(\mathrm{p}=0.05)$.

Thursday in 1997 was a day when we can observe a decrease $(\mathrm{p}=0.05)$.

Friday in 2006 witnessed a decrease and in 2013 a growth $(\mathrm{p}=0.05)$.

With classical rates of reliability, we refuted the assumption of existence of the day-of-the-week effect in the examined period. When examining the day-of-the-week effect, we managed to identify 
only scarce anomalies and we can generally say that in the examined period, the examined indices do not show marks of market anomalies, and we cannot confirm the existence of the market anomaly denominated the day-of-the-week.

Although the day-of-the-week effect on the stock market seems to have disappeared over the time and due to financial crises, the empirical testing of historical data shows that certain aboveaverage/below-average returns occurred.

Examining the day-of-the-week effect at the Prague Stock Exchange, we managed to find an anomaly only in $2010 \mathrm{p}=0.01$ (the Monday effect), which however did not occur again in any other year.

The other days when we suspected the occurrence of anomalies were Wednesday $(2000,2011)$ and Friday (2010, 2018) at $\mathrm{p}=0.05$ (Wednesday) and $\mathrm{p}=0.1$ (Friday).

The Prague Stock Exchange contains only a few titles that are under the scrutiny of many analysts and traders, which is also the reason why we can expect the semi-strong form of the efficient market hypothesis. This is underlined by the composition of the PX index, where 4-5 titles make up about $80 \%$ of the index's market capitalisation. The different behaviour of the Prague Stock Exchange over the day, unlike other stock exchanges (Frankfurt or London) is influenced by the opening/closing hours, as Prague closes trading at 5 p.m. CET, while most of the Stock Exchanges close later. And the 3-4 biggest stock titles according to the market capitalisation represented in the index, are traded at the surrounding European stock exchanges (also after the closing hour in Prague), and therefore this kind of time anomaly is only hard to show at the Prague index, unlike the other (American) indices observed herein.

On the one hand, we can see at the BCPP (Prague Stock Exchange) that the price adapts to new information before it is made public (evidence of insider trading) and on the other hand, it takes several weeks for the market to evaluate the new information.

\section{CONCLUSION}

If we summarise the results of the analyses, we can say that in the examined period no relationship was proved between the day of the week and the stock returns. We can assume that this kind of anomaly has been suppressed by modern times, when everyone with access to the Internet can search a large amount of information. In the past, people had to rely on the stock exchange information published by institutions that deliberately tried to schedule the publication of negative information at the end of the business week hoping that the pessimistic mood would calm down over the weekend when the stock exchange is closed, and that the impact after the stock exchange opens again on Monday will not be as strong as it was when the negative information was disclosed The reduced occurrence of the day-of-the-week effect in recent years can also be explained by the development of new investment instruments that have lower transaction costs and can hedge the risks more easily. The distribution of returns over the week also varies from market to market, which may be due to the characteristics of the markets and the trading mechanisms applied in the markets.

Although this study failed to prove the occurrence of the day-of-the-week effect, it does not necessarily mean that the other market anomalies do not occur in the given markets. Therefore, it would be appropriate to continue the tests, and to test the presence of other seasonal anomalies, too.

\section{REFERENCES}

Al-Khazali, O. \& Mirzaei, A. (2017). Stock market anomalies, market efficiency and the adaptive market hypothesis: Evidence from Islamic stock indices. Journal Of International Financial Markets, Institutions And Money, 51, 190-208. https://doi.org/10.1016/j.intfin.2017.10.001 
Bachalier, L. (1900). THÉORIE MATHÉMATIQUE DU JEU (3.rd ed.).

Bildik, R. (2011). The day-of-the-week effect for Istanbul stock exchange: a stochastic dominance approach. Journal of Applied Finance \& Banking, 1(4), 223-238. http://www.ssrn.com/abstract=598904

Cowles, A. \& Jones, H. E. (1937). Some A Posteriori Probabilities in Stock Market Action. Econometrica, 5(3). https://doi.org/10.2307/1905515

Connolly, R. A. (1989). An Examination of the Robustness of the Weekend Effect. The Journal Of Financial And Quantitative Analysis, 24(2), 133-169. https://doi.org/10.2307/2330769

Cross, F. (2018). The Behavior of Stock Prices on Fridays and Mondays. Financial Analysts Journal, 29(6), 67-69. https://doi.org/10.2469/faj.v29.n6.67

Fama, E. F. (1970). Efficient Capital Markets: A Review of Theory and Empirical Work. The Journal Of Finance, 25(2), 383-417. https://doi.org/10.2307/2325486

Fama, E. F. \& French, K. R. (1993). Common risk factors in the returns on stocks and bonds. Journal Of Financial Economics, 33(1), 3-56. https://doi.org/10.1016/0304-405X(93)90023-5

Fama, E. F. (1991). Efficient Capital Markets: II. The Journal Of Finance, 46(5), 1575-1617. https://doi.org/10.2307/2328565

Filáček, J., Kapička, M., \& Vošvrda, M. (1998). Efficiency Market Hypothesis: Testing on the Czech Capital Market. Czech Journal Of Economics And Finance, 48(9), 554-566.

Fortune, P. (1998). Weekends can be rough: revisiting the weekend effect in stock prices. Working Paper: Federal Reserve Bank Of Boston, 98(6), 1-20.

Gibbons, M. R. \& Hess, P. (1981). Day of the Week Effects and Asset Returns. The Journal Of Business, 54(4), 579-596. https://doi.org/10.1086/296147

Golder, S. A. \& Macy, M. W. (2011). Diurnal and Seasonal Mood Vary with Work, Sleep, and Daylength Across Diverse Cultures. Science, 333(6051), 1878-1881. https://doi.org/10.1126/science.1202775

Haugen, R. A. (2000). Modern Investment Theory (5 ed.). Pearson.

Chang, E. C., Pinegar, J. M., \& Ravichandran, R. (1993). International Evidence on the Robustness of the Day-of-the-Week Effect. The Journal Of Financial And Quantitative Analysis, 28(4), 497-513. https://doi.org/10.2307/2331162

Khuntia, S. \& Pattanayak, J. K. (2018). Adaptive market hypothesis and evolving predictability of bitcoin. Economics Letters, 167(1), 26-28. https://doi.org/10.1016/j.econlet.2018.03.005

Lakonishok, J. \& Smidt, S. (1988). Are Seasonal Anomalies Real? A Ninety-Year Perspective. Review Of Financial Studies, 1(4), 403-425. https://doi.org/10.1093/rfs/1.4.403

Madureira, L. L., Leal, L. L., \& ,R. P. C. (2001). Elusive anomalies in the Brazilian stock market. International Review Of Financial Analysis, 10(2), 123-134. https://doi.org/10.1016/S10575219(01)00045-X

Malkiel, B. G. (2003). The Efficient Market Hypothesis and Its Critics. Journal Of Economic Perspectives, 17(1), 59-82. https://doi.org/10.1257/089533003321164958

Samuelson, P. A. (1973). Proof That Properly Discounted Present Values of Assets Vibrate Randomly. The Bell Journal Of Economics And Management Science, 4(2), 369-374. https://doi.org/10.2307/3003046

Sias, R. W. \& Starks, L. T. (1995). The Day-of-the-Week Anomaly: The Role of Institutional Investors. Financial Analysts Journal, 51(3), 58-67. https://doi.org/10.2469/faj.v51.n3.1906

Yongxin, L. (2009). Discussing on Trend to Efficient Market Hypothesis of Securities and Futures Market. In 2009 International Conference on Information Management, Innovation Management and Industrial Engineering, 149-152. IEEE. https://doi.org/10.1109/ICIII.2009.346

Zhang, J., Lai, Y., \& Lin, J. (2017). The day-of-the-Week effects of stock markets in different countries. Finance Research Letters, 20(1), 47-62. https://doi.org/10.1016/j.frl.2016.09.006 